\title{
Avaliação de sistemas de janela para suporte a decisões de projeto quanto ao equilíbrio de ganhos de luz e calor
}

\author{
Evaluating window systems for decision support regarding \\ the balance of daylight and heat gains
}

\section{Kamila Mendonça de Lima Rosana Maria Caram}

\section{Resumo

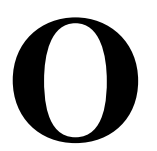

projeto de janelas considera os efeitos do meio externo, tais como o ganho de calor solar e a iluminação natural, os quais podem ser conflitantes. Este trabalho avalia o desempenho de diferentes alternativas de sistemas de janela para suporte a decisões de projeto quanto ao equilíbrio de ganhos de luz e calor no ambiente interno, com ênfase no uso de escritório no contexto do clima quente e úmido. Para isso, simulações computacionais integradas utilizando os programas Daysim e EnergyPlus foram realizadas, considerando-se o acionamento das lâmpadas apenas quando a luz natural não é suficiente para atender ao uso do ambiente. Foram variados o percentual de área de abertura, o tipo de vidro e o ângulo de sombreamento, simultaneamente, identificando-se soluções de compromisso quanto aos critérios de disponibilidade e uniformidade da luz e demanda de energia elétrica no ambiente. $\mathrm{O}$ controle solar pelo uso de dispositivo de proteção solar apresentou resultados substancialmente melhores que o controle solar apenas pela redução da transmissão da radiação solar do vidro. A avaliação realizada contribui para o aprofundamento da compreensão do impacto de diferentes variáveis de projeto nos fenômenos que caracterizam o desempenho da abertura de uma edificação.

Palavras-chaves: Simulação integrada. Suporte a decisão. Iluminação natural. Brises.

\footnotetext{
Abstract

Designing windows requires dealing with the external environmental conditions, which may be conflicting, such as solar gains and daylight. This paper evaluates the performance of different alternatives for window systems to support design decisions on the balance of light and heat gains in the indoor environment, focusing on offices in a hot and humid climate. In order to do this, integrated computer simulations using the Daysim and EnergyPlus softwares were performed, considering the activation of electric lighting only when daylight was not sufficient to meet the usage requirements. The variables were window-to-wall ratio, glazing type and shading angle, simultaneously. Compromise solutions were found regarding the criteria of availability and uniformity of daylight and electricity demand in the indoor environment. It was observed that solar control through the use of shading devices presented substantially better results than solar control by reducing transmission of solar radiation by the glass. The assessment conducted contributes to increase understanding about the impact of different design variables on the phenomena characterising the performance of fenestration systems.

Keywords: Integrated simulation. Decision-making support. Daylighting. Shading devices.
} 


\section{Introdução}

O projeto do sistema de abertura é fundamental para a adequação climática de uma edificação, contribuindo para o conforto dos usuários no ambiente e para o uso consciente de energia elétrica para condicionamento dele. Nesse processo, o projetista lida com os efeitos do meio externo, os quais podem ser conflitantes, tais como o ganho de calor e a iluminação natural, ambos provenientes da radiação solar. Em climas quentes e úmidos quase sempre apenas o segundo elemento é desejado.

Conforme destacado por Bittencourt (1993), nessas regiões a principal demanda referente ao condicionamento passivo é por resfriamento, por meio de soluções que contemplem a necessidade simultânea de ventilação natural, sombreamento e filtro da iluminação natural. Esses aspectos estão diretamente relacionados ao projeto da janela.

Diversos trabalhos mostram que uma seleção adequada das características de geometria e propriedades da janela pode permitir aperfeiçoar o desempenho térmico ou luminoso do ambiente (BOKEL, 2007; GHISI; TINKER, 2005; SANTOS; BASTOS, 2008; TZEMPELIKOS et al., 2010).

Em se tratando de sistemas com protetores solares para atendimento aos requerimentos térmico e luminoso de forma simultânea, pode-se destacar a utilização de componentes que combinem sombreamento e iluminação natural indireta por reflexão (PEREIRA, 1992), ou o potencial de diferentes geometrias de brises externos para melhorar o desempenho do ambiente interno (ALZOUBI; AL-ZOUBI, 2010; DAVID et al., 2011; LIMA; BITTENCOURT; CARAM, 2013).

A respeito dos temas citados, dois importantes aspectos vêm sendo estudados com o auxílio da simulação computacional. $\mathrm{O}$ primeiro deles consiste em se vincular o funcionamento do sistema de iluminação elétrica à disponibilidade de luz natural por meio de simulação integrada, como feito em Didoné e Pereira (2010) e em outras referências, de forma a identificar o potencial do aproveitamento da iluminação natural para a economia de energia elétrica destinada a lâmpadas e condicionamento do ar.

Tzempelikos e Athienitis (2007) identificaram uma redução de até $12 \%$ desse consumo total em relação a soluções de janela sem sombreamento, e Manzan et al. (2014), uma redução de até $18 \%$. Os primeiros consideraram variações na área de abertura, transmissão de luz pelo protetor solar e controle dele para casos em Montreal (Canadá). Os últimos consideraram o acionamento e geometria do dispositivo como parâmetros para identificar um conjunto de soluções ótimas para o caso de Trieste (Itália).

Comparando soluções de janela sem brise, janelas com dispositivos fixos e com dispositivos automatizados no caso da Dinamarca e considerando o aproveitamento de ventilação natural no verão, Nielsen, Svendsen e Jensen (2011) obtiveram uma diferença de até $16 \%$ na demanda total de energia entre os casos que apresentaram o melhor e o pior desempenho para dada orientação.

O segundo aspecto que vem sendo estudado com o auxílio da simulação computacional é relacionado ao caráter polivalente da janela e consiste na avaliação de diferentes critérios para identificar soluções de compromisso (ganho de luz com controle dos ganhos de calor pela abertura, por exemplo) para conforto e uso eficiente de energia, discutindo-se a própria forma de se usarem os indicadores de desempenho em procedimentos de suporte à decisão.

Nesse sentido, pode haver proposição de índices (DAVID et al., 2011), definição de metas e identificação gráfica de soluções projetuais (OCHOA et al., 2012), ou ainda a aplicação de metodologias de avaliação multicritério (FONTENELLE; BASTOS, 2014). Relacionadas a tais procedimentos, a classificação e a ordenação quantitativa de cenários de projeto arquitetônico são formas objetivas de auxiliar o projeto arquitetônico, tal como exemplificado por Roulet et al. (2002).

No contexto apresentado, as características da janela podem ser tratadas como variáveis de projeto e combinadas entre si, permitindo o conhecimento de alternativas com potencial de apresentar melhor desempenho em determinado contexto. Os estudos citados, entre outros da literatura, fornecem informações que podem auxiliar o processo decisório, concentrando-se principalmente na proporção de área de janela, propriedades do envidraçamento e propriedades do sistema de proteção/controle solar, características que, de forma isolada, são objeto frequente de avaliações.

Contudo, nas etapas iniciais do projeto arquitetônico, podem ser realizadas escolhas de combinações. Diminuir o tamanho da janela e usar um vidro claro com um brise mediano, usar uma abertura maior com um vidro de baixa transmissão sem brise ou usar uma abertura grande com vidro mediano e um brise que sombreie por mais tempo são exemplos de diferentes opções que podem ser 
levantadas para uma solução de controle do ganho de calor solar com a maior quantidade de iluminação natural possível.

O estudo do efeito dessas variáveis de projeto quando combinadas ainda não é consolidado, especialmente no caso de localidades de baixa latitude, onde é provável que o controle das propriedades da janela tenha grande impacto no balanço dos ganhos térmicos e luminosos, dada a grande incidência de radiação solar.

Diante dos aspectos tratados, este trabalho tem como objetivo avaliar o desempenho de diferentes alternativas de sistemas de janela para suporte a decisões de projeto quanto ao equilíbrio de ganhos de luz e calor no ambiente interno, com ênfase no uso de escritório no contexto do clima quente e úmido. Considera-se o funcionamento de sistemas artificiais condicionado ao aproveitamento da iluminação natural, e têm-se como critérios de análise o conforto luminoso e a demanda de energia para condicionamento artificial.

\section{Material e métodos}

A seguir são descritos o objeto de estudo e os procedimentos metodológicos desta pesquisa.

\section{Delimitação do objeto e contexto climático}

O sistema de janela estudado é composto de um envidraçamento e brises horizontais externos, conforme a Figura 1. A espessura do vidro é de 5 $\mathrm{mm}$, e o protetor solar possui 10 aletas igualmente espaçadas entre si, com a maior dimensão horizontal igual à da janela.
Foi considerado um ambiente com características típicas do uso de escritório, com localização correspondente à cidade de Maceió, AL. O local apresenta clima quente e úmido (NIMER, 1979), caracterizando-se por alta umidade, pequenas variações de temperatura (diárias, sazonais e anuais) e radiação solar intensa (Figura 2). A janela sombreada é uma estratégia fundamental nesse tipo de clima para controle da radiação solar, que influenciará a iluminação e os ganhos térmicos.

\section{Montagem da análise paramétrica}

Para a definição dos cenários avaliados, foram consideradas três variáveis de projeto da janela, percentual de área de abertura, tipo de vidro e ângulo de sombreamento, nos valores indicados na Figura 3. Combinando-se as variáveis entre si, obteve-se um total de 27 cenários.

Além disso, foram estudadas duas orientações diferentes, norte e oeste, que podem ser consideradas respectivamente uma orientação favorável e uma orientação crítica em termos de disponibilidade de luz e incidência de radiação solar na localidade estudada. Na primeira ocorrem alturas solares maiores e incidência solar inclinada em relação à fachada (ângulos de incidência elevados) nos períodos do ano mais amenos. $\mathrm{Na}$ segunda há radiação solar direta todos os dias do ano no período da tarde, com baixos ângulos de incidência com relação à janela.

O módulo de escritórios simulado está destacado na Figura 4. Os resultados foram extraídos para um dos ambientes, de acordo com a orientação desejada.

Figura 1 - Esquema com tipo de janela (texto em vermelho) e fatores considerados (texto em cinza)

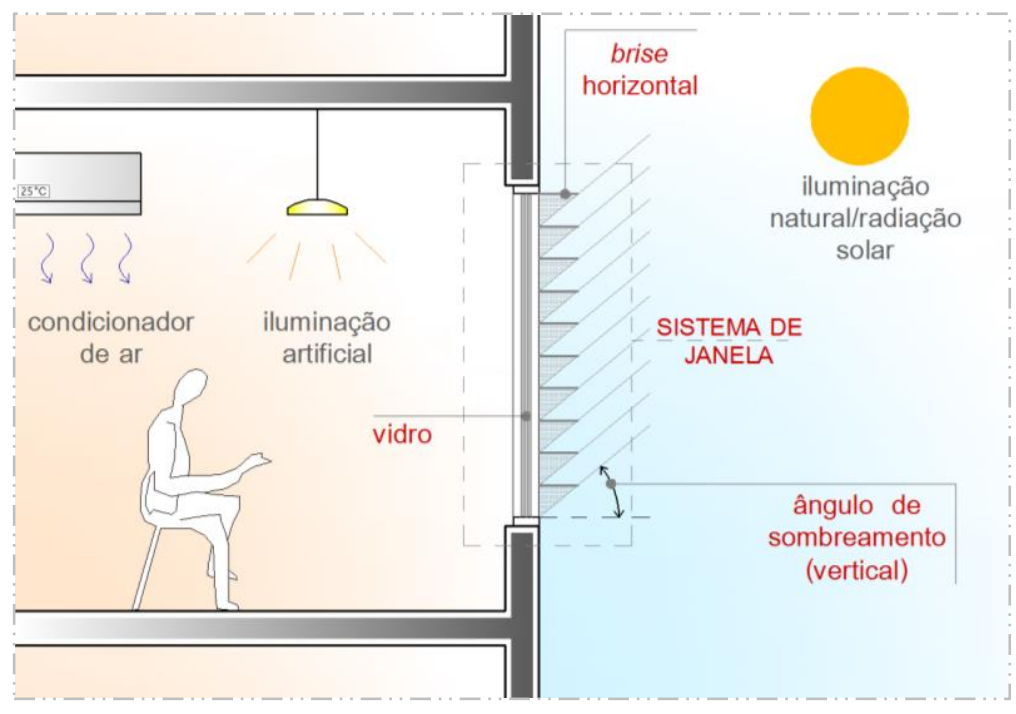


Figura 2 - Temperatura do ar e intensidade de radiação solar de um ano climático de referência de Maceió, AL

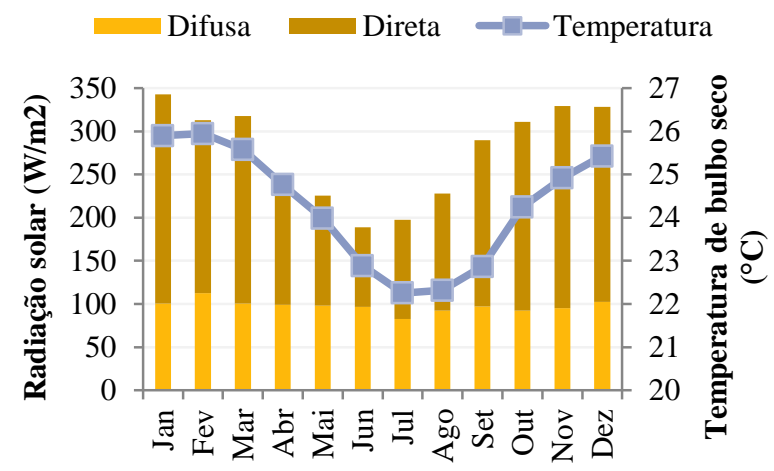

Fonte: Laboratório de Conforto Ambiental e Eficiência energética em Edificações (2013).

Figura 3 - Dados e nomenclatura de cada variável de projeto para definição dos cenários analisados

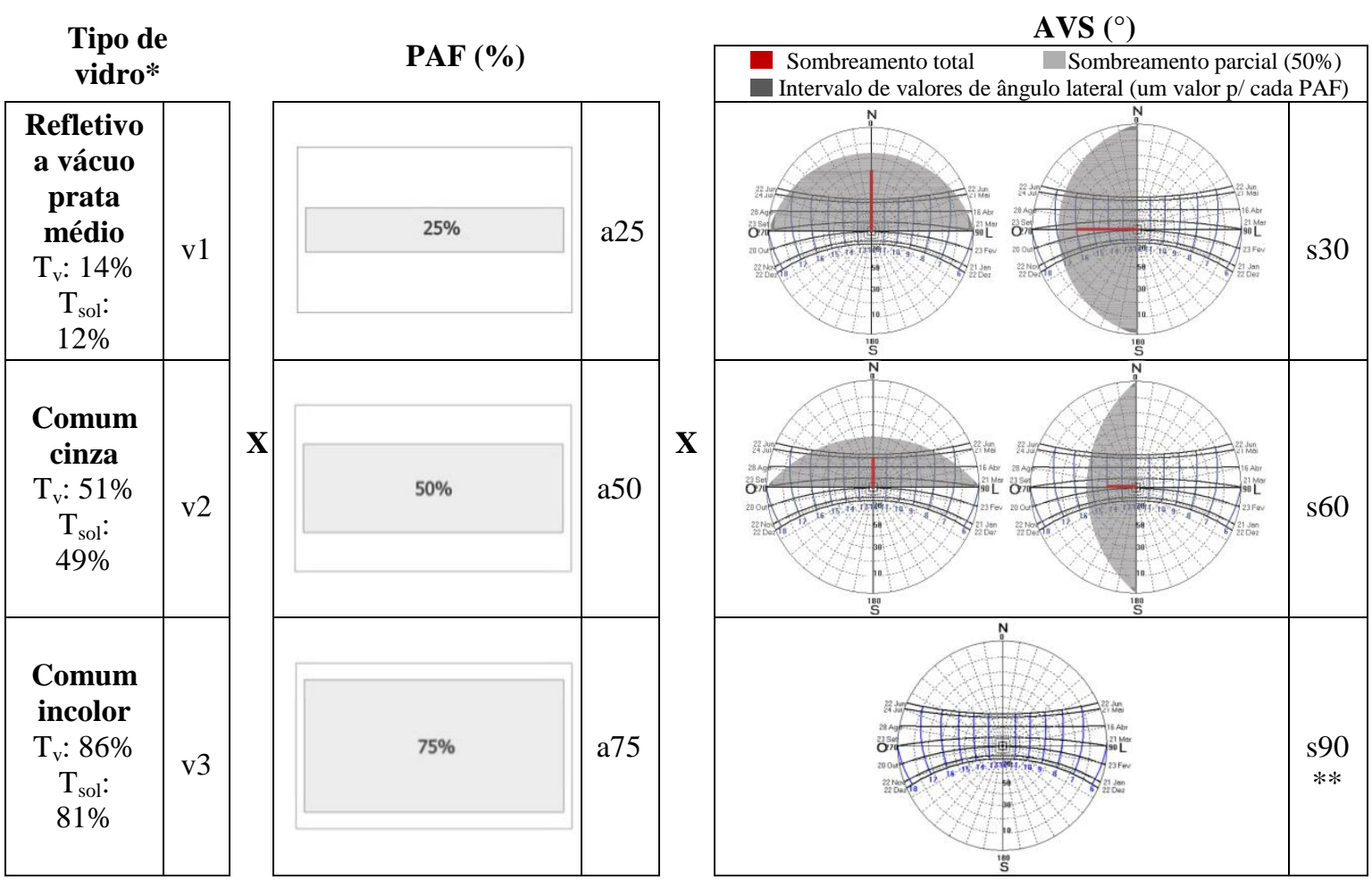

Nota: *Transmissão visível $\left(T_{v}\right)$ e solar $\left(T_{\text {sol }}\right)$ para ângulo de incidência normal; $e^{* *} 90^{\circ}$ representa a janela totalmente exposta (sem dispositivos de sombreamento).

Fonte: Caram (2002).

Figura 4 - Dimensões do módulo de ambientes simulado, com indicação das faces que contêm janelas

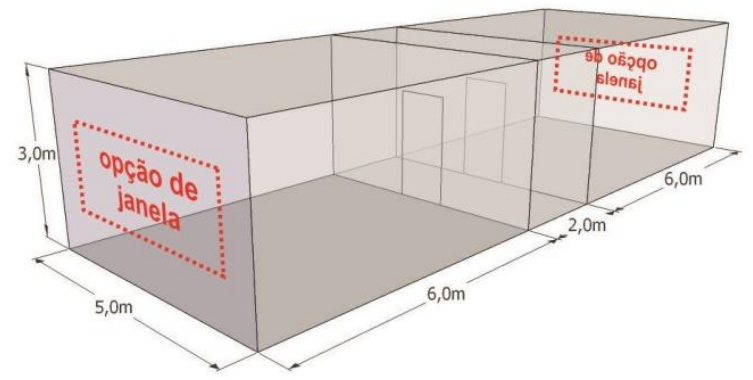




\section{Simulações}

Foram realizadas simulações integradas em dois passos principais. $O$ primeiro consiste na simulação de iluminação natural no software Daysim (REINHART, 2013), que emprega a ferramenta Radiance para simular a iluminação natural e agrega um modelo comportamental (chamado LightSwitch). Aqui ele foi utilizado para simular o acionamento do sistema de luz artificial apenas quando a luz natural não é suficiente para se obter a iluminância de tarefa no ambiente, gerando um arquivo de saída com os horários de acionamento das lâmpadas. A Tabela 1 contém os principais dados de entrada definidos nessa etapa.

O segundo passo é a simulação energética, em que se utiliza o software EnergyPlus (U.S. DEPARTMENT..., 2013), no qual os dados do modelo são inseridos incluindo-se as schedules de funcionamento do sistema de iluminação artificial, obtidas no primeiro passo. A Tabela 2 destaca os principais dados inseridos no programa. A simulação considerou os períodos ocupados.

A respeito da demanda de energia elétrica, considerou-se um sistema de lâmpadas de potência instalada igual a $10 \mathrm{~W} / \mathrm{m}^{2}$, suficiente para se obter um nível de eficiência energética igual a B segundo a classificação do regulamento técnico RTQ-C (BRASIL, 2010). O documento estabelece valores de referência para uma classificação de eficiência energética da edificação, entre eles o valor máximo de densidade de potência de iluminação segundo o uso do ambiente.

De forma semelhante, foi identificado o valor de um coeficiente de performance do sistema de condicionamento do ar, mínimo para se obter a classificação A ou B, o qual foi de 3,5. Para o cálculo da demanda de energia elétrica para esse sistema no ambiente simulado, o valor obtido para a carga térmica de resfriamento foi dividido pelo coeficiente referido.

\section{Análise dos dados}

Os dados de saída das simulações foram analisados considerando-se critérios de quantidade e uniformidade da iluminação, e demanda de energia elétrica para lâmpadas e condicionamento do ar, sendo cada critério expresso por um indicador de desempenho.

Tabela 1 - Parâmetros de simulação no Daysim 3.1

\begin{tabular}{c|c}
\hline Plano de trabalho & $0,75 \mathrm{~m}$ a partir do piso \\
\hline Pontos/sensores & Malha ortogonal de 30 pontos \\
\hline Refletâncias & Piso=0,30; teto $=0,75 ;$ paredes $=0,60 ;$ brises $=0,50$ \\
\hline Parâmetros do Radiance & $\begin{array}{c}\text { Complexidade } 2: \text { ab } 7, \text { ad } 1500, \text { as } 100, \text { ar } 300, \text { aa } 0,1, \mathrm{r} 6, \\
\text { st } 0,15, \mathrm{sj} 1,00, \mathrm{lw} 0,004, \mathrm{dj} 0,00, \mathrm{ds} 0,20, \mathrm{dr} 2, \mathrm{dp} 512\end{array}$ \\
\hline \multicolumn{2}{c}{ OightSwitch } \\
\hline Oluminância mínima & 8h às $18 \mathrm{~h}$ - Rotina gerada pelo software \\
\hline Tipo de usuário & A00 lx \\
\hline Controle das lâmpadas & Ativo \\
\hline
\end{tabular}

Tabela 2 - Parâmetros de simulação no EnergyPlus 7.2

\begin{tabular}{c|c}
\hline \multicolumn{2}{|c}{ Construção } \\
\hline Paredes, piso e teto & $\begin{array}{c}\text { Paredes com janela: Bloco cerâmico com seis furos de seção quadrada }+ \\
\text { argamassa branca }\left(\mathrm{U}=2,48 \mathrm{~W} / \mathrm{m}^{2} \mathrm{~K}\right) ; \text { Demais paredes, piso e teto: adiabáticas }\end{array}$ \\
\hline Brises & Aluzinc (Condutividade $=176,9 \mathrm{~W} / \mathrm{mK})$ no objeto WindowMaterial:Blind \\
\hline \multicolumn{2}{c}{ Ocupação e ganhos internos } \\
\hline Ocupação & 8h às $12 \mathrm{~h}$ e $14 \mathrm{~h}$ às $18 \mathrm{~h}$ de segunda à sexta; $8 \mathrm{~h}$ às $12 \mathrm{~h}$ aos sábados \\
\hline Pessoas & 4 ocupantes; 0,8 clo (inverno) e 0,5 clo (verão) \\
\hline Ganhos internos & $120 \mathrm{~W} /$ pessoa + Equipamentos $\left(15 \mathrm{~W} / \mathrm{m}^{2}\right)+$ Lâmpadas $\left(10 \mathrm{~W} / \mathrm{m}^{2}\right)$ \\
\hline \multicolumn{2}{c}{ HVAC } \\
\hline Ar condicionado & Módulo IdealLoadsAirSystem \\
\hline Funcionamento & Ativo durante todo o período de ocupação \\
\hline Termostato & $25^{\circ} \mathrm{C}$ \\
\hline Taxa de infiltração & $1 \mathrm{ren} / \mathrm{h}$ \\
\hline
\end{tabular}


Com relação à disponibilidade de luz, foi analisada a ocorrência de intervalos de iluminâncias, conforme proposto por Nabil e Mardaljevic (2006), baseando-se na noção de iluminâncias úteis (UDI, do inglês Useful Daylight Illuminances). As iluminâncias abaixo de 100 lx são consideradas insuficientes; aquelas entre $100 \mathrm{e}$ 500 são úteis, com possibilidade de complementação por meio de luz artificial. Já a faixa entre 500 e 2000 lx representa as condições em que a luz natural como única fonte é suficiente para proporcionar condições para a execução de atividades no ambiente. As iluminâncias acima de 2.000 lx são consideradas desnecessárias e/ou com potencial de causar desconforto visual e térmico.

Para análise da uniformidade, utilizou-se como referência o indicador da norma NBR ISO/CIE 8995-1 (ABNT, 2013), que é dado pela razão entre o valor mínimo e o valor médio das iluminâncias na área analisada. A norma indica que esse valor não deve ser menor que 0,7 na tarefa e que não deve ser menor que 0,5 no entorno imediato. Para que esse também seja um indicador dinâmico, foi calculada a uniformidade para cada intervalo de tempo analisado, e depois o percentual do tempo total em que ela se encontra acima dos valores de referência mencionados. $\mathrm{O}$ modelo analisado consiste em um ambiente genérico, não se tendo definição de quais são as áreas de tarefa e de entorno. Assim sendo, o valor mínimo de uniformidade se refere à média de todos os pontos da sala simulados (30 pontos), de forma que, quando a uniformidade está acima de 0,7 , qualquer ponto da sala estaria adequado para a tarefa, e quando ela está acima de 0,5 a sala toda atenderia à norma enquanto entorno imediato.

No que se refere à demanda de energia, foi obtido o somatório anual de energia elétrica necessária para condicionamento do ar e iluminação artificial, para manutenção das condições internas destacadas na seção anterior. Ao fim, foi feita uma síntese para auxílio a procedimentos de escolha, na forma de uma tabela simplificada contendo uma possibilidade de ordenação das alternativas de sistema de janela consideradas.

\section{Resultados}

A seguir são mostradas diferentes análises para permitir a discussão dos fenômenos envolvidos no desempenho da tipologia de abertura estudada.

\section{Iluminação natural}

Os resultados obtidos referentes à iluminação natural no ambiente estão ilustrados nas Figuras 5, 6, 7 e 8. Todos os valores indicados nos gráficos são a média dos 30 pontos simulados do plano de trabalho. O primeiro aspecto a ser observado é a ocorrência de iluminâncias.

Observa-se na Figura 5 que os totais obtidos para os diferentes intervalos avaliados são semelhantes para as duas orientações simuladas. Naturalmente, a disponibilidade de luz é maior conforme se aumenta a área de abertura, a transmissão luminosa do vidro e o ângulo horizontal de sombreamento (reitera-se que se trata do ângulo em relação à normal ao plano da janela, de forma que ângulos menores indicam mais obstrução).

Nota-se que, apesar de algumas alternativas proporcionarem menor quantidade de luz natural na comparação com outras, elas podem ser melhores do ponto de vista de diminuírem a ocorrência de iluminâncias acima de 2.000 lx, aqui consideradas desnecessárias. Nesse sentido, observa-se que, quando o vidro é incolor (v3) ou cinza (v2), alternativas com maior obstrução apresentam maior ocorrência de iluminância útil (entre 100 e 2.000 lx) do que nas condições com a janela mais exposta, ainda que as primeiras apresentem menos luz no somatório total. Tal comportamento ocorre mesmo quando a abertura analisada é pequena (a25).

Diante desse aspecto, relacionado à disponibilidade de luz na localidade analisada, indica-se a necessidade de o projetista estar atento às iluminâncias excessivas, para que não se assuma que um projeto de iluminação que resulte em maior quantidade de luz seja sempre desejado. Além disso, se houver no ambiente algum anteparo ou elemento que provoque variações significativas de iluminação entre as diferentes porções do ambiente, apenas a complementação com uma análise da distribuição da luz e/ou do ofuscamento irá permitir avaliar as condições de iluminação natural de forma mais precisa.

Por fim, observa-se que o vidro refletivo de cor prata (v1), que possui apenas $12 \%$ de transmissão visível, apresenta um desempenho muito pobre quando comparado aos demais vidros simulados, dada a grande ocorrência média de iluminâncias abaixo de 100 1x. Observa-se também que mudança para o vidro de transmissão média (v2) é suficiente para diminuir significativamente a ocorrência desse intervalo de iluminâncias.

A Figura 6 mostra a faixa de iluminâncias entre 500 e $2.0001 x$ isoladamente. Essa é a faixa-alvo e o principal indicador de disponibilidade de luz aqui considerado, representando a possibilidade de iluminação do ambiente de escritório tendo a luz natural como única fonte. 
Figura 5 - Ocorrência de diferentes faixas de iluminâncias (média de 30 pontos)

Norte

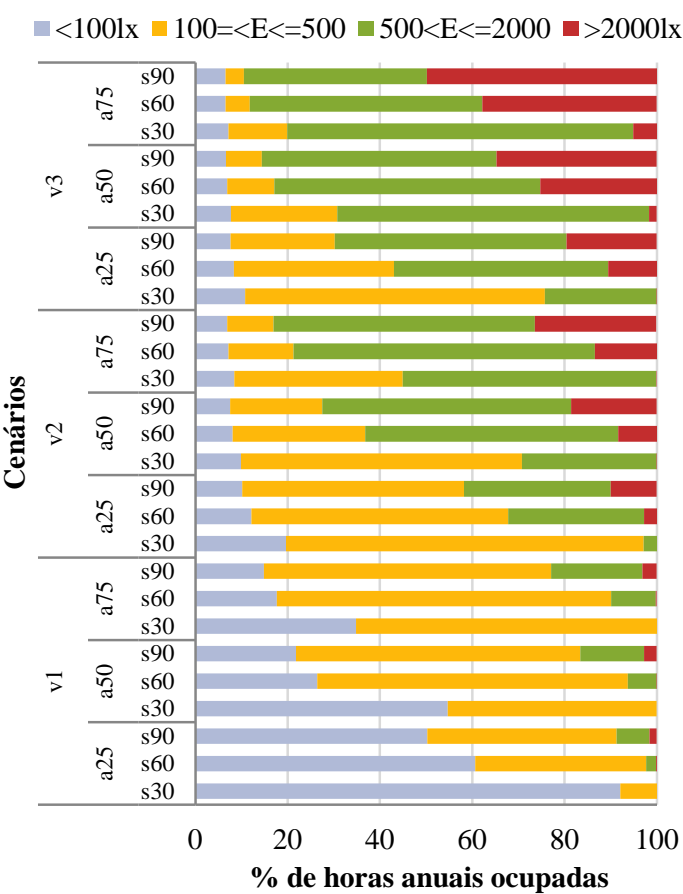

(a)
Oeste

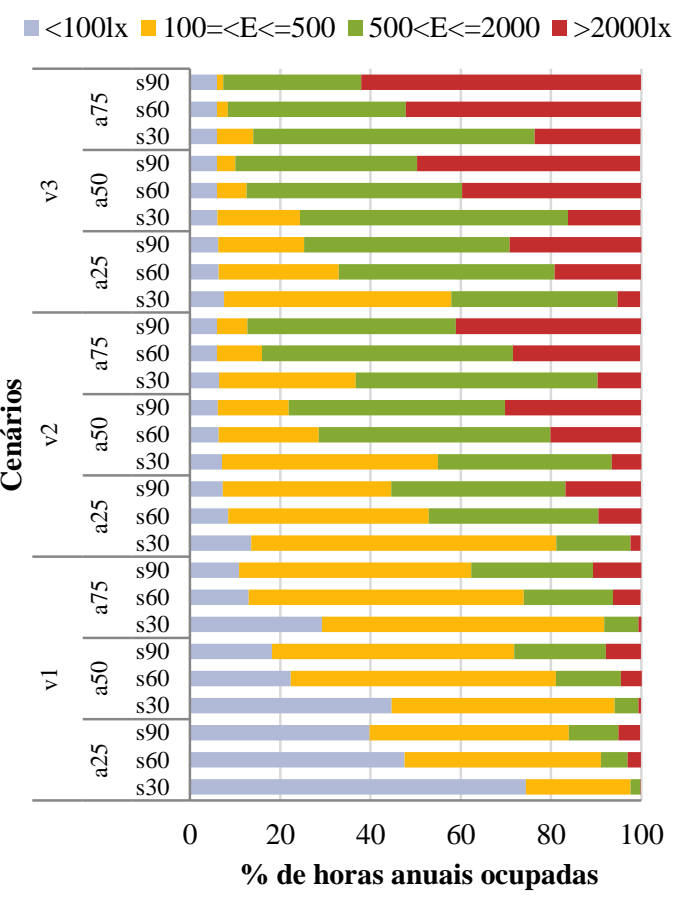

(b)

Figura 6 - Ocorrência de iluminâncias entre 500 e 2.000 Ix nas horas ocupadas (média de 30 pontos)

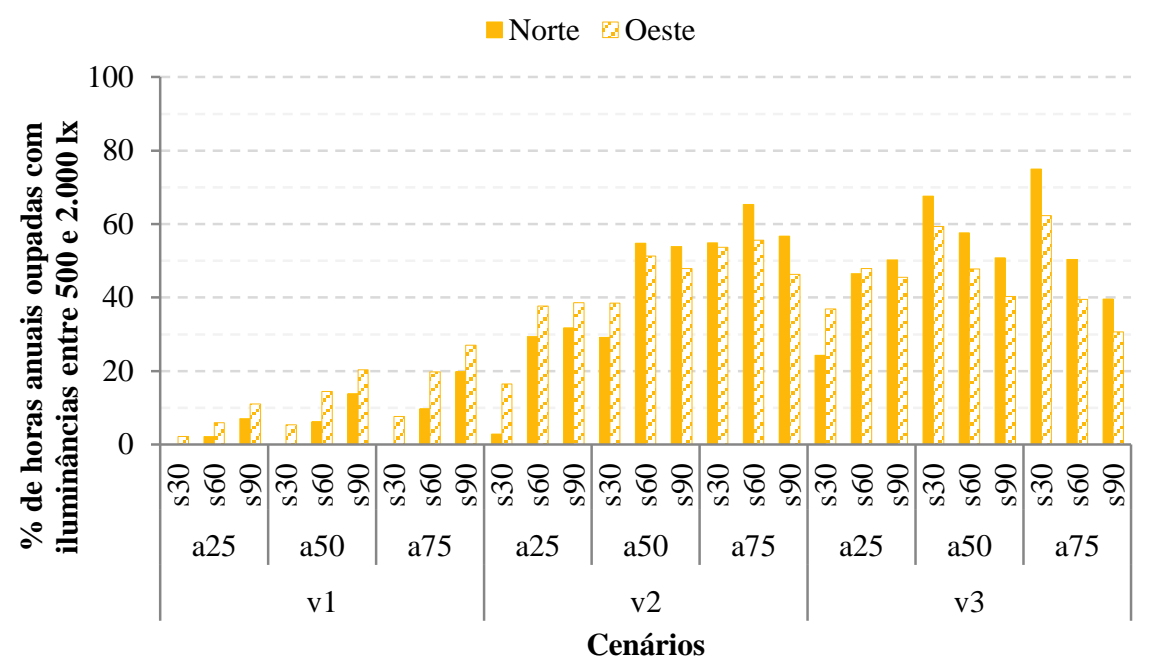

Observa-se que a escolha adequada do sistema de janela pode permitir a independência do sistema de iluminação artificial em uma média de até $75 \%$ das horas anuais ocupadas na orientação norte, e em uma média de até $62 \%$ das horas na orientação oeste. Por outro lado, esse percentual, que é um indicador bastante exigente, pode ser muito baixo quando a janela é pequena (a25) combinada com sombreamento (s30) e vidro cinza (v2) ou em todas as condições que combinam vidro refletivo (v1) e sombreamento (s30). Neste último caso, o percentual tratado chega a ser nulo.

Mesmo assim, a presença de protetores solares também pode aumentar a ocorrência de iluminâncias úteis entre 500 e 2.000 lx em relação aos casos com a janela exposta nos cenários com vidro incolor (v3) e abertura média (a50) ou grande (a75). Isso também ocorre com os casos v2a75s60 e v2a50s60, de forma que mesmo a combinação de vidro cinza e protetores solares 
pode proporcionar independência do sistema artificial no ambiente estudado em uma média de mais da metade das horas anuais ocupadas nas duas orientações simuladas.

Entre as variáveis de projeto analisadas, o tipo de vidro apresenta uma significativa influência nesse indicador de desempenho da iluminação natural (ocorrência de iluminâncias entre 500 e 2.000 1x). Aqui tal efeito pode ser ainda mais significativo do que aquele causado pela variação na área de abertura da janela.

A Figura 7 ilustra o percentual de ocorrência de iluminâncias nessa faixa entre 500 e 2.000 lx, relacionando os valores analisados em média no gráfico anterior e a área do ambiente onde ocorrem, conforme os diferentes pontos simulados. São apresentados dois casos para cada orientação, os quais podem ser considerados de alta e baixa uniformidade da iluminação.
Naturalmente pode haver uma curva no sentido da profundidade do ambiente, pois a abertura é lateral. No cenário com vidro cinza, área de abertura grande (a75) e sombreamento de $30^{\circ}$, essa curva é pouco acentuada, havendo distribuição de luz favorável para a realização de atividades em diferentes locais do ambiente. Já no cenário que combina vidro claro e área de abertura grande sem sombreamento há menor uniformidade da ocorrência desses percentuais, que devido às iluminâncias excessivas são baixos nas regiões próximas à janela.

Entende-se que um percentual de ocorrência de iluminâncias úteis entre 500 e 2.000 lx acima de $50 \%$ justifica a opção por uma estratégia de aproveitamento da luz natural, pois dessa forma não haveria qualquer necessidade de lâmpadas para atender aos requisitos mínimos de iluminação para atividades de escritório em mais da metade do tempo ocupado.

Figura 7 - Ocorrência de iluminâncias entre 500 e 2.000 lx em função dos pontos no ambiente Cenários v2a75s30 e v3a75s90

Norte

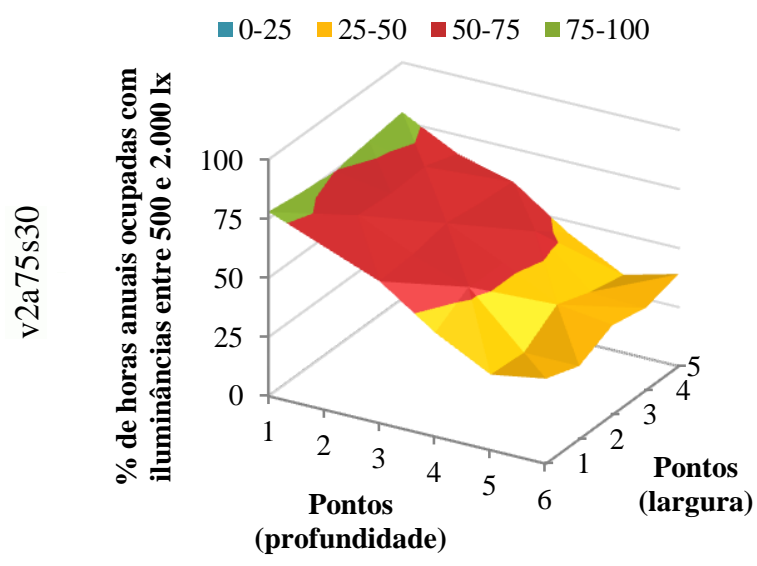

$\square 0-25 \quad \square 25-50 \quad \square 50-75 \quad \square 75-100$

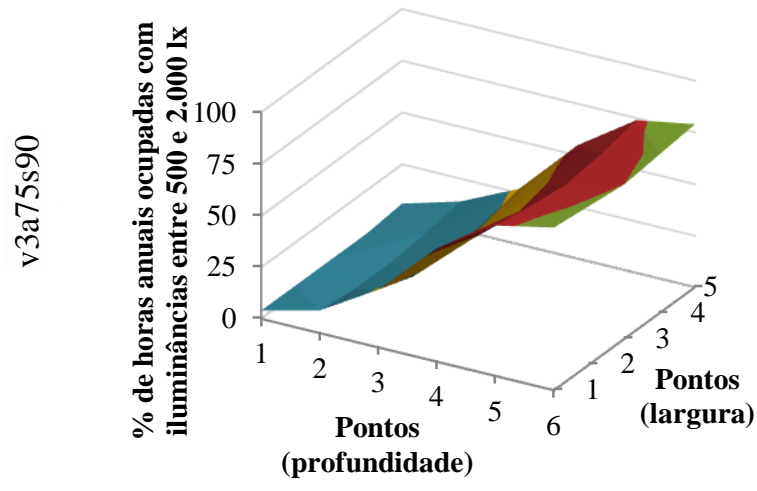

\section{Oeste}

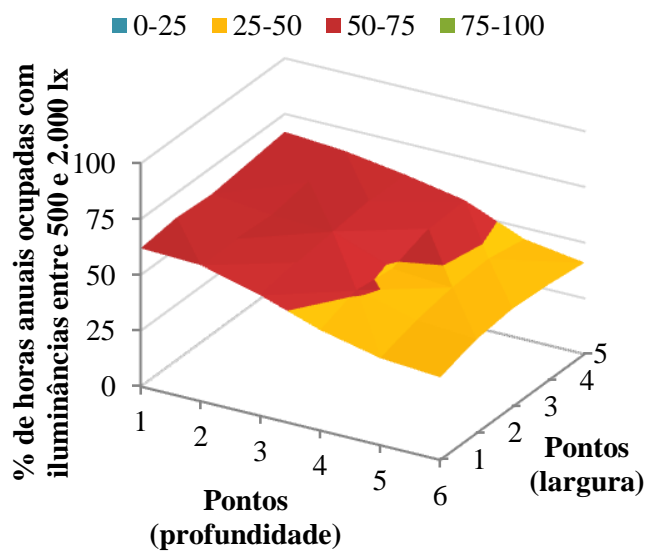

$\square 0-25 \square 25-50 \square 50-75 \square 75-100$

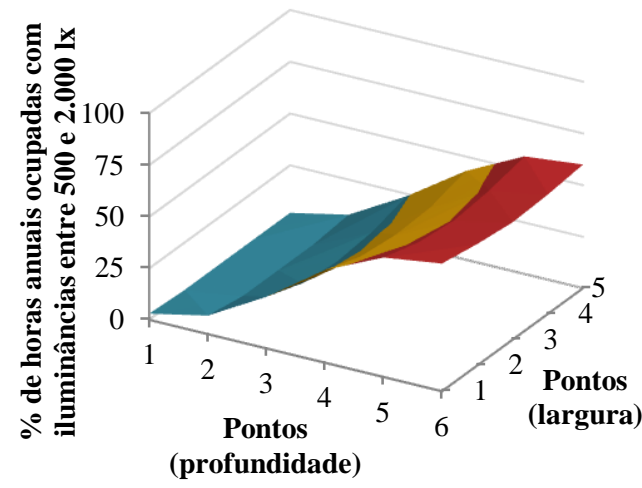


Nesse sentido, os resultados referentes ao cenário v2a75s30 na orientação norte indicam que esse total (representado pelas faixas vermelhas e verdes no gráfico) seria atingido em pouco mais de $3 / 5 \mathrm{da}$ área do ambiente, que corresponde a $18 \mathrm{~m}^{2}$ na área total de $30 \mathrm{~m}^{2}$. São atingidos, inclusive, valores próximos de $80 \%$ das horas ocupadas. $\mathrm{Na}$ orientação oeste também há predominância da área do ambiente que atenderia a esse requisito sobre aquela que não atenderia: no gráfico observa-se que aproximadamente $3 / 4$ do ambiente se enquadrariam no critério definido, o que equivaleria a $22,5 \mathrm{~m}^{2}$.

Por outro lado, no cenário v3a75s90 foram obtidos percentuais de ocorrência das iluminâncias entre 500 e $2.000 \mathrm{~lx}$ abaixo de $50 \%$ (faixas amarelas e azuis no gráfico) em mais de $3 / 5$ da área do ambiente nas duas orientações simuladas.

Tais resultados apontam uma possibilidade de variação significativa das ocorrências de iluminâncias nas diferentes áreas do ambiente. Contudo, mesmo nos casos em que a distribuição é pouco uniforme, sempre há uma porção do ambiente em que a iluminação natural como principal fonte de luz é possível. Além disso, sendo o problema as iluminâncias excessivas, indica-se a possibilidade de que os brises possam ser dimensionados de acordo com as diferentes porções verticais da janela, para bloquear mais a luz na porção frontal do ambiente
A análise dos índices de uniformidade da iluminação é apresentada a seguir, com resultados na Figura 8. O ângulo de sombreamento, que apresenta influência menor na ocorrência das iluminâncias úteis, aqui é a variável entre as três estudadas que possui maior impacto no resultado obtido.

Observa-se que a condição de uniformidade acima de 0,5 é atingida em pelo menos $80 \%$ das horas anuais ocupadas na maior parte dos casos analisados (24 de 27) na orientação norte. Dois dos casos que não se enquadram nesse resultado correspondem a alternativas de janela com sombreamento de $60^{\circ}$, onde provavelmente não se tem área de aletas suficiente para reflexão da luz para o fundo da sala (tal como haveria nos cenários com sombreamento maior) na mesma magnitude dos demais casos.

No caso v1a75s90 acredita-se que o valor obtido, menor que os demais, deve-se ao fato de o tamanho da abertura e a transmissão do vidro não serem comparativamente suficientes para que as regiões no fundo da sala recebam iluminação em valores mais homogêneos em relação aos valores próximos à janela, os quais, por sua vez, são altos em função da ausência de proteção solar. $\mathrm{Na}$ orientação oeste o percentual de horas ocupadas nas quais a uniformidade acima de 0,5 é atingida encontra-se entre $25 \%$ e $80 \%$, variando principalmente em função do ângulo de sombreamento.

Figura 8 - Uniformidade da iluminação no período ocupado (considera os 30 pontos do plano de trabalho)

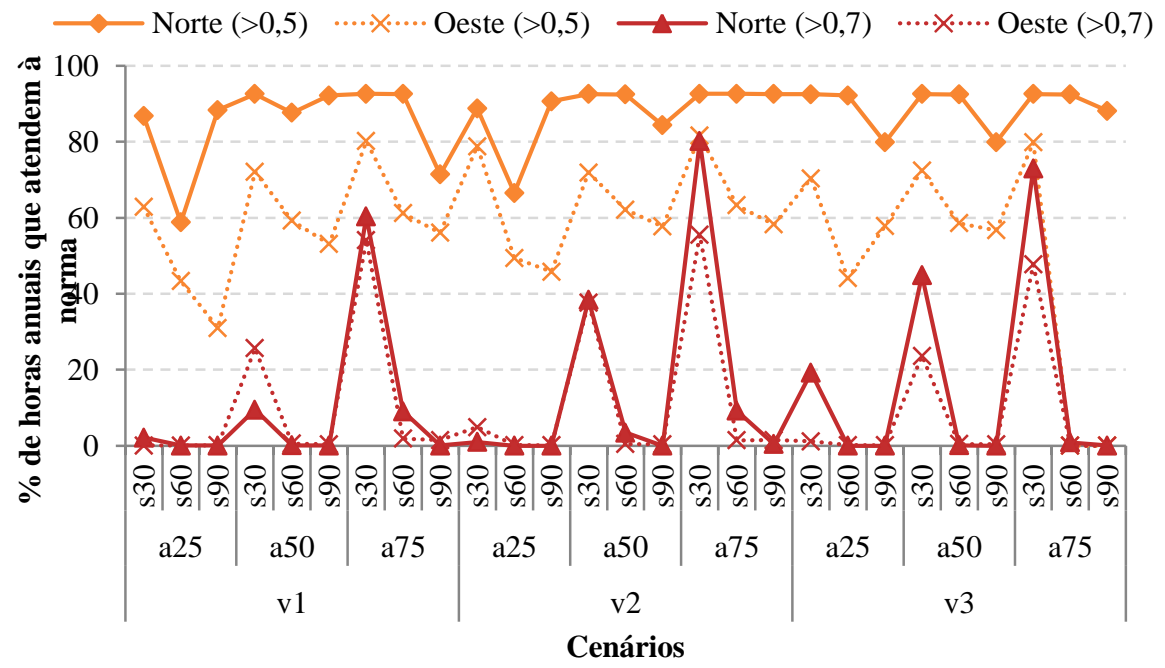


Quando se analisa a uniformidade própria para a área de tarefa (acima de 0,7), a combinação de brises de ângulo vertical de sombreamento igual a $30^{\circ}$ e abertura média (a50) ou grande (a75) se destaca, sendo as únicas condições em que o percentual de horas anuais que atendem ao critério analisado é maior que $10 \%$, chegando a $80 \%$ na orientação norte. Dessa forma, a opção por um sombreamento mais restritivo nas condições analisadas poderia ser feita sem prejuízos à uniformidade da iluminação natural, desde que a abertura seja média ou grande, e até mesmo com vidro refletivo se a abertura for grande (a75). Reitera-se que a aplicação desse critério de desempenho de maneira mais precisa dependeria da definição do leiaute do ambiente.

É possível fazer algumas considerações sobre o desempenho considerando os dois indicadores de iluminação natural analisados. Observa-se que há variação significativa nos resultados de acordo com a escolha do sistema de janela, de forma que a alteração de qualquer uma das variáveis de projeto analisadas pode significar alteração importante no resultado.

Nota-se que é possível haver diferença entre os casos com melhor desempenho com relação à disponibilidade de luz e com relação à uniformidade. $\mathrm{O}$ vidro refletivo, por exemplo, que apresenta desempenho ruim no que se refere à UDI, pode estar entre os casos com maior uniformidade (tal como ocorre com o cenário v1a75s30).

Para a escolha de alternativas que apresentem bom desempenho com relação aos dois aspectos da luz natural estudados (disponibilidade e uniformidade), entre as analisadas, observa-se que o indicador de desempenho mais restritivo é a uniformidade da luz na tarefa (requerimento acima de 0,7$)$. Isso indica que, se a escolha da alternativa de sistema de janela for feita priorizando-se essa uniformidade, há maior chance de se obter melhor desempenho também no critério da quantidade de iluminação. Já de forma inversa, priorizando-se as alternativas com maior disponibilidade de luz, pode-se obter desempenho muito baixo para a uniformidade.

Escolhendo-se, então, os casos com melhor desempenho quanto à uniformidade, que nas duas orientações analisadas correspondem ao caso v2a75s30, observa-se que este caso obteve o resultado favorável também com relação às iluminâncias úteis, atingindo mais da metade do tempo na condição desejada (entre 500 e 2.000 1x). Escolhendo-se o segundo melhor caso com relação à uniformidade, o caso v3a75s30, cujo desempenho é bem próximo do anterior, constata- se que essa opção de janela é o cenário com melhor desempenho em relação à ocorrência de iluminâncias úteis, atingindo $75 \%$ de horas ocupadas dentro do critério de uniformidade na orientação norte, e $62 \%$ na orientação oeste.

Portanto, a combinação de aberturas médias ou grandes, vidro incolor e maior sombreamento pode ser uma alternativa que apresenta comparativamente alta disponibilidade de luz e alta uniformidade. A complementação dessa análise será feita com a avaliação do desempenho com relação à demanda de energia elétrica, a seguir.

\section{Demanda de energia elétrica}

Com relação à demanda de energia para iluminação e condicionamento do ar, as análises a seguir tratam dos resultados referentes ao ambiente de escritório com as características anteriormente descritas. A Figura 9 indica a demanda total de energia obtida a partir das simulações, separandose as parcelas para cada finalidade (lâmpadas e condicionadores de ar)

Nota-se que o efeito de cada varável considerada isoladamente (área de abertura, tipo de vidro e ângulo de sombreamento) depende muito do valor fixado para as demais, de forma a ser difícil identificar uma tendência clara para cada variável.

Nas situações estudadas, quando o vidro é o refletivo de baixa transmissão (v1), a alteração na área de abertura e no ângulo de sombreamento não tem efeito significativo na demanda total de energia na orientação norte, os quais ficam em torno de $1.500 \mathrm{kWh}$, quaisquer que sejam as demais opções de área de abertura e sombreamento.

Utilizando-se vidro refletivo nessa orientação, os ganhos de calor e de iluminação provocados pela combinação das demais características da janela são compensados entre si: ao se comparar situações com ângulo de sombreamento $30^{\circ} \mathrm{com}$ as de ângulo $60^{\circ}$, observa-se que, no segundo caso, há aumento do consumo com ar condicionado e redução com consumo de iluminação em relação ao primeiro, numa proporção tal que o consumo total fica semelhante.

Isso não ocorre nas situações com os demais tipos de vidro, casos em que a transparência à radiação solar é maior e o efeito das demais características da janela no resultado passa a ser mais significativo. Nota-se, por exemplo, como a escolha da área de abertura pode alterar o resultado quando o vidro é claro e sem sombreamento. Da mesma forma, considerando-se as diferentes orientações, o impacto da escolha das alternativas 
é maior na orientação oeste, a qual apresenta maior carga térmica de resfriamento.

Observa-se que o ângulo de sombreamento é a característica com maior impacto nos resultados quando o vidro é cinza ou incolor, especialmente na orientação oeste, onde há incidência de radiação solar no período da tarde ao longo de todo o ano na localidade estudada. Assim sendo, mesmo com a possível redução das iluminâncias, as alternativas que representam janelas sombreadas podem apresentar menor demanda de energia elétrica no somatório final em relação aos cenários com janela exposta (sem sombreamento).

Seria possível afirmar que isso ocorre exclusivamente devido ao papel da carga térmica de resfriamento na demanda total de energia. Contudo, isolando-se os casos com maior sombreamento (ângulo igual a $30^{\circ}$ ), nota-se que as melhores alternativas são aquelas que apresentam menor demanda para iluminação artificial. Apesar da parcela significativa que as cargas de resfriamento representam na demanda total, a carga referente à iluminação pode ser decisiva, pois, como visto anteriormente, o resultado da iluminação natural é bastante sensível à variação das características da janela, o que não ocorre com a carga térmica referida.

As Figuras 10 e 11 apresentam as alternativas de janela ordenadas a partir do caso que obteve menor demanda de energia para iluminação e condicionamento do ar ao caso com maior demanda. Os resultados indicam que há um potencial de redução da demanda de energia de até $34 \%$ em relação ao pior caso na orientação norte, e de $44 \%$ na orientação oeste. Observa-se que janelas com vidro incolor e ângulo de sombreamento de $30^{\circ}$ apresentaram melhor desempenho do que janelas pequenas com vidro de menor transmissão e sem sombreamento. Além disso, nota-se que o cuidado com a área de abertura também pode ser decisivo para reduzir a demanda de energia na orientação oeste.

O impacto do ângulo de sombreamento é verificado novamente quando o caso com vidro incolor (v3) com abertura grande (a75) deixa de estar entre os três melhores para figurar como o pior caso se o ângulo de sombreamento passar de $30^{\circ}$ para $90^{\circ}$ (condição sem protetores solares).

Diante dos aspectos apresentados, observa-se que, para se obter melhor desempenho com relação ao critério da demanda de energia para iluminação e condicionamento do ar nas condições estudadas, recomenda-se como indicação geral para a orientação norte evitar vidro refletivo e a combinação de janelas grandes com vidro claro sem brise. $\mathrm{Na}$ orientação oeste recomenda-se evitar janelas sem brise.

Por fim, ressalta-se que essa demanda de energia elétrica para iluminação artificial considera $o$ aproveitamento da iluminação natural simulandose um sistema manual de acionamento das lâmpadas. O consumo total poderia ser ainda menor caso fosse utilizado um sistema dimerizável de controle da iluminação.

Figura 9 - Demanda de energia elétrica para condicionamento do ar e iluminação artificial

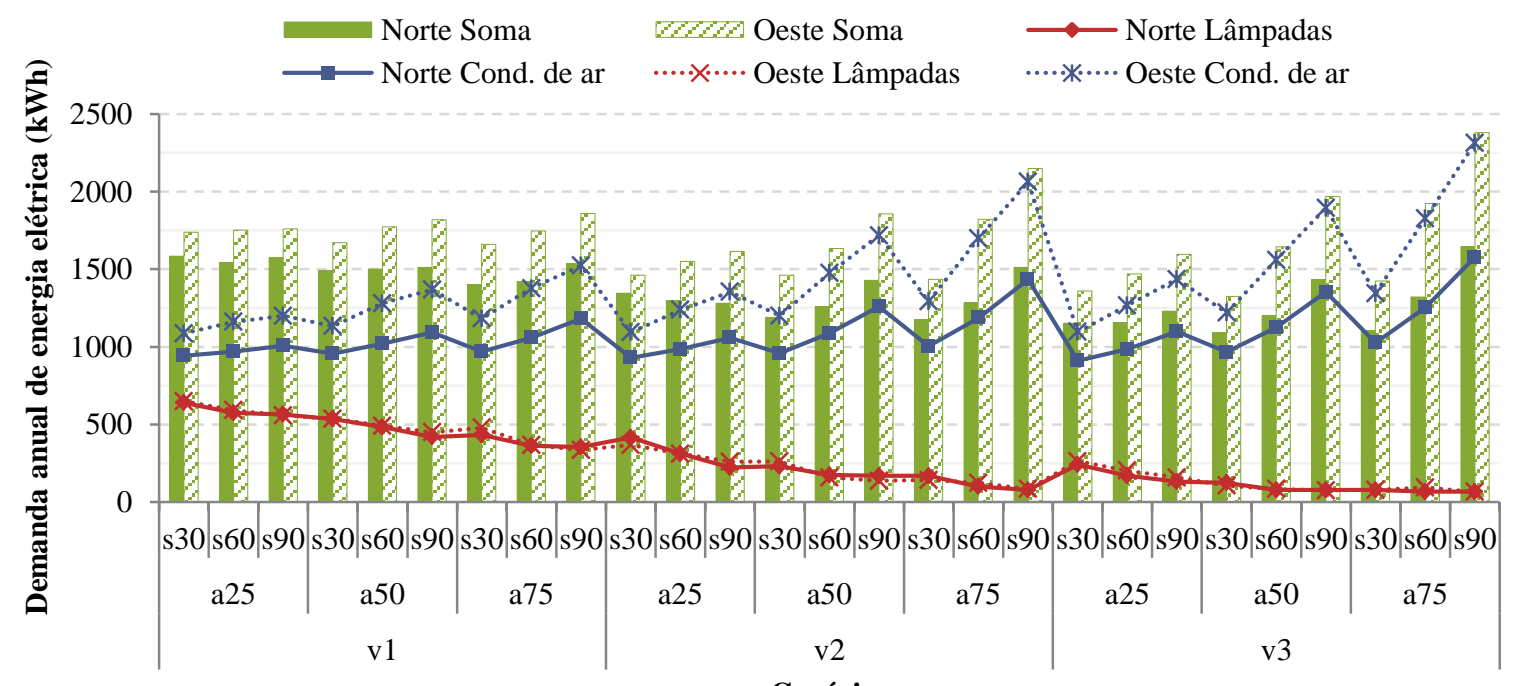

Cenários 
Figura 10 - Demanda de energia elétrica considerando as alternativas da orientação norte ordenadas

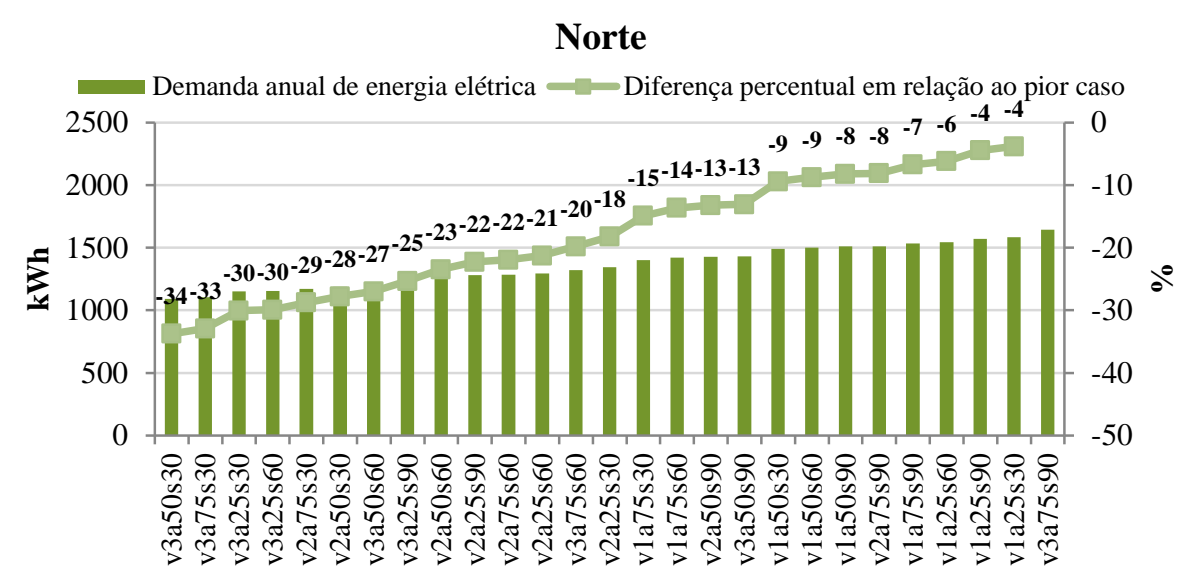

Figura 11 - Demanda de energia elétrica considerando as alternativas da orientação oeste ordenadas

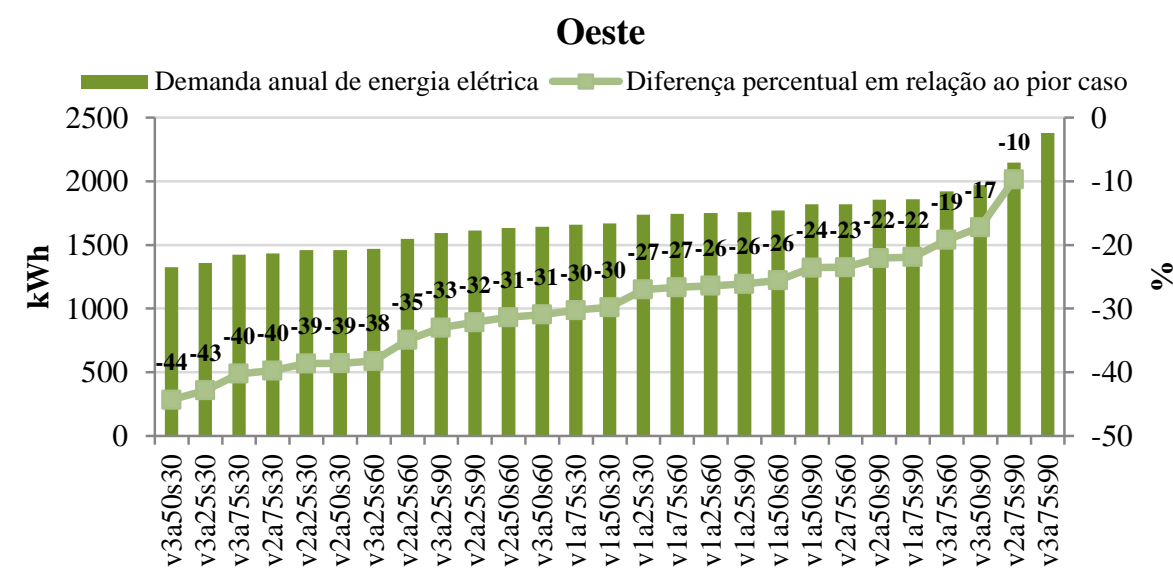

\section{Visualização conjunta}

A Tabela 3 sintetiza os resultados obtidos para os três indicadores de desempenho abordados neste trabalho, ilustrando uma classificação das alternativas de sistemas de janela estudadas e constituindo uma ferramenta simplificada de suporte direto a decisões de projeto.

Ela foi elaborada utilizando-se uma planilha eletrônica para ordenar as alternativas de acordo com o resultado quantitativo obtido, do melhor caso $\left(1^{\circ}\right)$ ao pior caso $\left(27^{\circ}\right)$, para cada um dos indicadores referidos. Com relação à uniformidade, apenas o valor de referência 0,7 foi indicado. Ele apresentou resultados mais restritivos, englobando ainda o outro critério de uniformidade (se a condição para iluminação de tarefa é atendida, a de iluminação de entorno certamente também o é).

Nota-se que a melhoria de desempenho (tendência à primeira colocação) com relação à iluminação e à uniformidade corresponde a valores maiores dos resultados obtidos nas simulações. Já com relação ao consumo de energia, sendo o objetivo minimizar a demanda, a classificação é do menor valor para o maior valor obtido. Foi utilizada uma escala de cores para auxiliar a visualização das classificações definidas.

A Tabela 3 pode permitir ao projetista, por exemplo, melhorar as características de uma janela de acordo com o critério que for considerado mais importante.

Considerando-se os critérios definidos e atribuindo-se o mesmo peso a todos deles, a alternativa de sistema de janela entre as analisadas que apresentou o melhor desempenho e que teria desempenho semelhante nas duas orientações analisadas é aquela com $75 \%$ de área de abertura, vidro incolor e ângulo de sombreamento igual a $30^{\circ}$. Se os pesos forem diferenciados, cenários distintos podem ser considerados para se obter melhor desempenho comparado, desde que haja proteção solar. 
Ambiente Construído, Porto Alegre, v. 15, n. 3, p. 117-133, jul./set. 2015.

Tabela 3 - Ordenação das alternativas de janela analisadas considerando os três critérios estudados (Continua...)

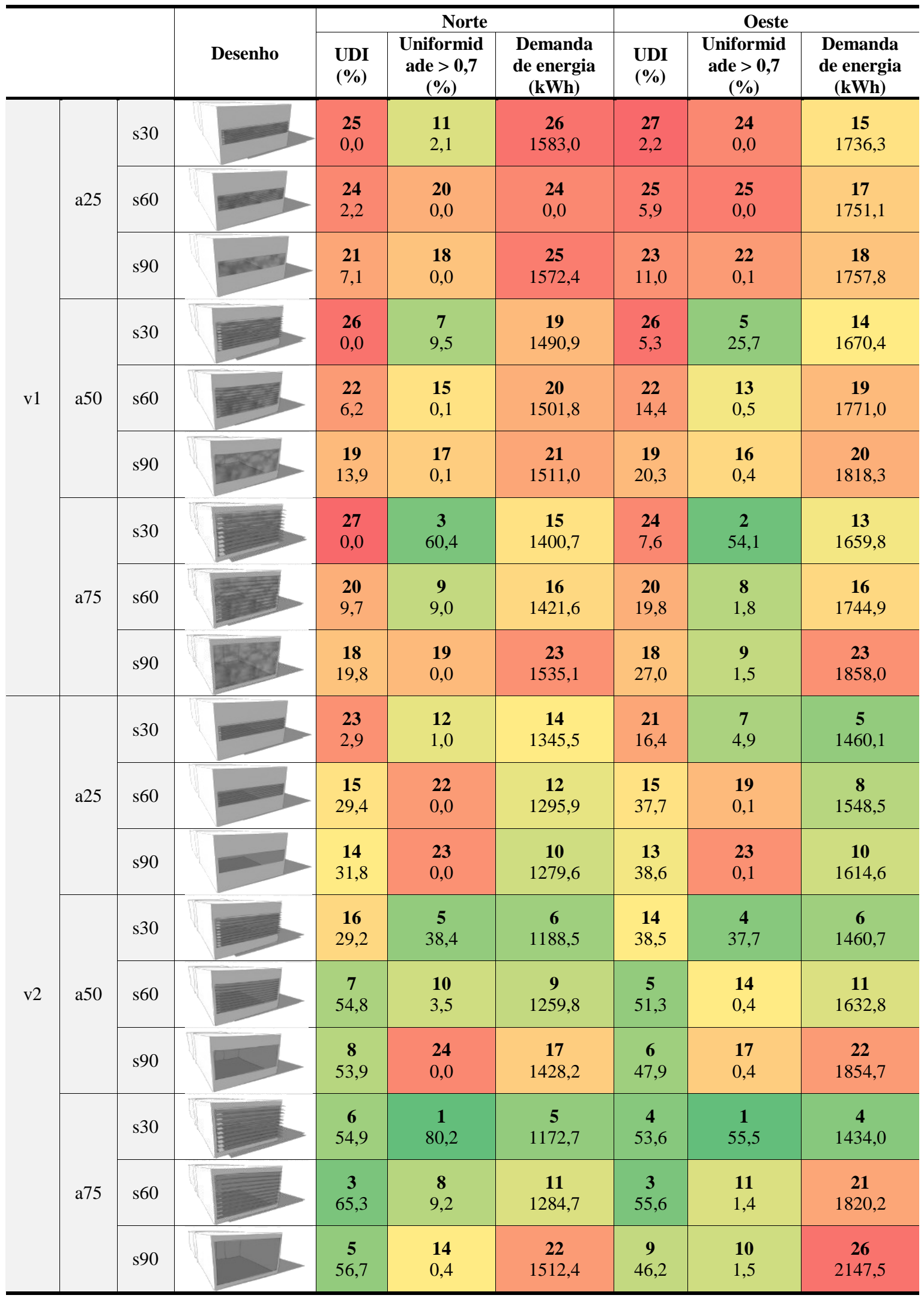

Nota: Legenda:

Melhor desempenho (1)

Pior desempenho (27) 
Tabela 3 - Ordenação das alternativas de janela analisadas considerando os três critérios estudados (continuação)

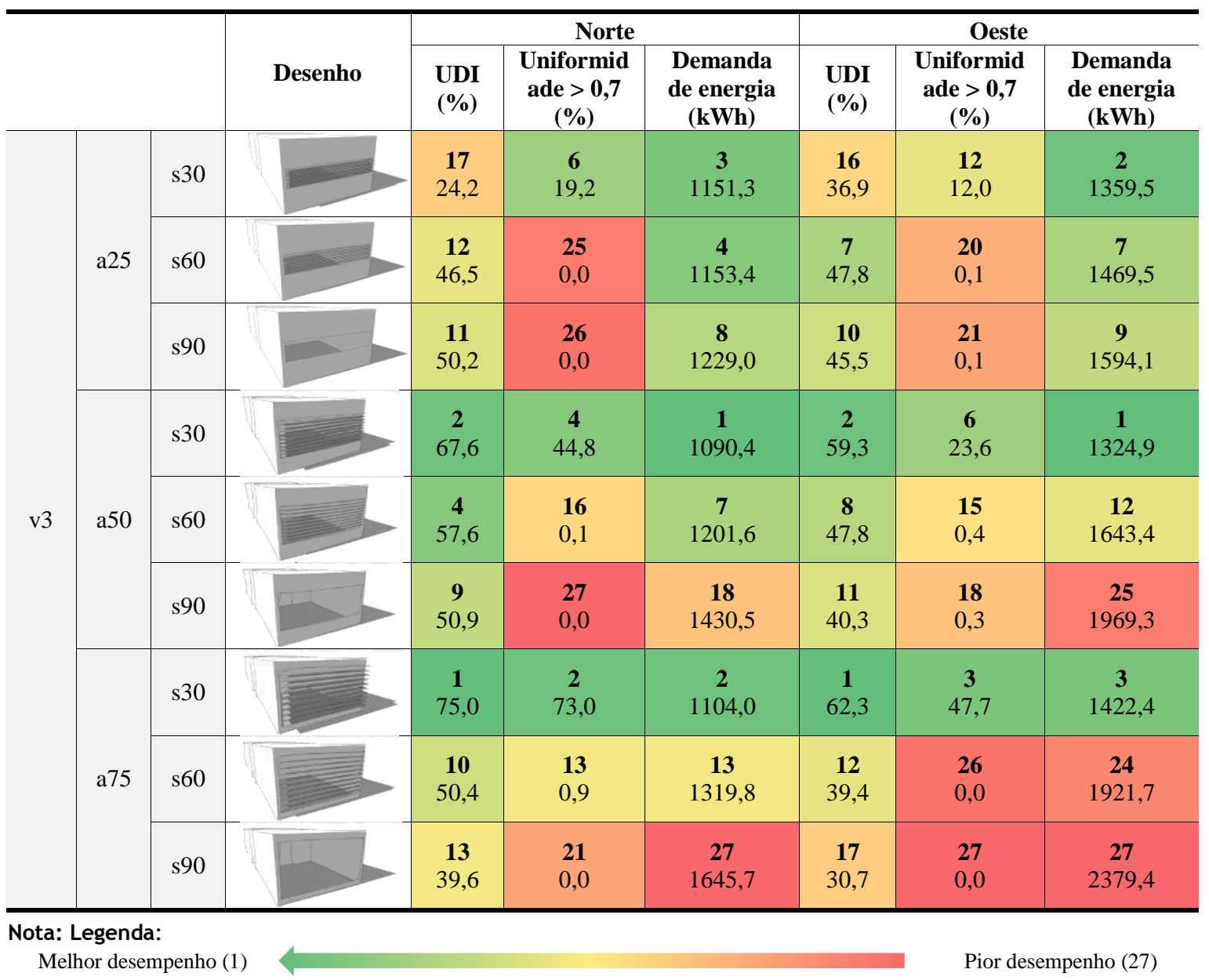

Conforme discutido anteriormente e agora visto de forma comparada, destaca-se o bom desempenho das alternativas com maior sombreamento e vidro mais transparente, que na localidade analisada e de forma comparativa entre os cenários estudados proporciona uma relação favorável entre ganho de iluminação natural e controle de ganho térmico, sendo inclusive melhores que as condições com a combinação de abertura pequena e vidro refletivo, que, em princípio, também poderia ser pensada como forma de controle solar.

Mesmo quando o vidro refletivo é combinado com áreas de abertura médias e grandes, o que é comum nos edifícios de escritório da prática corrente na cidade analisada, seu desempenho só é superior aos demais tipos de vidro estudados se houver proteção solar, e mesmo assim apenas com relação ao critério da uniformidade da iluminação.

\section{Considerações finais}

O trabalho apresentado avaliou o desempenho de diferentes alternativas de sistemas de abertura, considerando três critérios de análise: disponibilidade de luz natural, uniformidade da iluminação e demanda de energia elétrica para iluminação e condicionamento do ar. Dessa forma, buscou reunir informações para auxílio a decisões de projeto no que se refere aos ganhos de luz e calor no ambiente interno, os quais em localidade de clima quente são quase sempre aspectos conflitantes. Abordou o procedimento de análise com base em diferentes critérios, com ênfase no caso de escritórios em uma localidade de clima quente e úmido.

A análise foi realizada por meio de simulação computacional integrada utilizando os softwares Daysim e EnergyPlus, de forma a se considerar o aproveitamento da luz natural para acionamento das lâmpadas apenas quando esta primeira não fosse suficiente para oferecer condições de execução de tarefas de escritório. Além das informações obtidas, foi apresentado um quadro com uma proposta de classificação dos diferentes sistemas analisados, como forma simplificada de 
auxílio direto para situações de projeto nas condições estudadas.

Os resultados indicaram que é possível obter iluminâncias úteis no ambiente simulado em uma média de até $75 \%$ das horas anuais ocupadas, bem como índices de uniformidade de tarefa (razão entre iluminâncias mínima e média igual ou maior que 0,7 ) em até $80 \%$ do tempo na orientação norte. Com relação à demanda de energia elétrica, observou-se que a seleção adequada do tipo de abertura entre aquelas analisadas pode significar redução de até $34 \%$ na demanda anual na orientação norte, e de até $44 \%$ na orientação oeste, comparando-se o pior e o melhor caso simulado.

Nas condições analisadas, o controle solar pelo uso de dispositivo de sombreamento apresentou resultados substancialmente melhores do que o controle solar apenas pela redução da transmissão da radiação solar do vidro, resultados que se afinam com os obtidos por Fontenelle e Bastos (2014), em estudo de caso de seis alternativas de abertura para um edifício na cidade do Rio de Janeiro. Assim, o impacto do sombreamento, cuja importância como estratégia já é amplamente conhecida, foi aqui identificado como possivelmente superior ao impacto das demais variáveis analisadas no que se refere ao equilíbrio de ganhos de luz e calor no contexto estudado.

Tratando-se de limitações e recomendações, observa-se ser possível dar continuidade ao processo de definição de soluções de compromisso para além do ponto de vista comparativo aqui empregado, considerando-se metas de desempenho e agregando-se outros critérios, tais como custo financeiro e conforto visual. Quanto às variáveis de projeto, é possível explorar o efeito de outras características relacionadas ao sombreamento, além do ângulo vertical de obstrução aqui considerado, devido à importância dessa variável nos resultados. Além disso, a mesma análise aqui realizada pode ser aplicada a outros contextos climáticos.

Diante dos aspectos apresentados, a abordagem de critérios de desempenho que podem ser conflitantes permitiu apontar soluções de compromisso e aprofundar a compreensão do impacto de diferentes variáveis de projeto nos fenômenos que caracterizam o desempenho da abertura de uma edificação. Reafirma-se que a escolha adequada de tais sistemas pode alterar significativamente o desempenho do ambiente quanto aos ganhos de luz e calor para conforto ambiental e uso de energia, nas quantidades destacadas anteriormente.

Além disso, o trabalho apresentado oferece suporte a uma decisão mais informada quanto ao desempenho luminoso e energético de sistemas de janela, importantes condicionantes que compõem o projeto arquitetônico.

\section{Referências}

ALZOUBI, H. H.; AL-ZOUBI, A. H. Assessment of Building Façade Performance in Terms of Daylighting and the Associated Energy Consumption in Architectural Spaces: vertical and horizontal shading devices for southern exposure facades. Energy Conversion and Management, v. 51, n. 9, p. 1592-1599, ago. 2010.

\section{ASSOCIAÇÃO BRASILEIRA DE NORMAS} TÉCNICAS. NBR ISO/CIE 8995-1: iluminação de ambientes de trabalho: parte 1: interior. Rio de Janeiro, 2013.

BITTENCOURT, L.S. The Regional Context. In: Ventilation as a Cooling Resource for WarmHumid Climates: na investigation on perforated block wall geometry to improve ventilation inside low-rise buildings. Tese (Doutorado em Environment and Energy Studies) - Architectural Association Graduate School, 1993.

BOKEL, R. M. J. The Effect of Window Position and Window Size on the Energy Demand For Heating, Cooling and Electric Lighting. In: BUILDING SIMULATION, 10., Delft, 2007. Proceedings... Delft, 2007.

BRASIL. Ministério do Desenvolvimento, Indústria e Comércio Exterior. Instituto Nacional De Metrologia, Normalização e Qualidade Industrial. Portaria n..$^{\circ}$ 372, de 17 de setembro de 2010. Diário Oficial da União, Brasília, DF, 18 de setembro de 2010.

\section{CARAM, R. M. Estudo e Caracterização de} Fachadas Transparentes Para Uso na Arquitetura: ênfase na eficiência energética. Tese (Livre-Docência) - Escola de Engenharia de São Carlos, Universidade de São Paulo, São Carlos, 2002.

DAVID, M. et al. Assessment of the Thermal and Visual Efficiency of Solar Shades. Building and Environment, v. 46, n. 7, p. 1489-1496, 2011.

DIDONÉ, E. L.; PEREIRA, F. O. R. Simulação Computacional Integrada Para a Consideração da Luz Natural na Avaliação do Desempenho Energético de Edificações. Ambiente Construído, Porto Alegre, v. 10, n.4, p. 139-154, out./dez. 2010. 
FONTENELLE, M. R.; BASTOS, L. E. G. The Multicriteria approach in the Architecture Conception: defining windows for an office building in Rio de Janeiro. Building and Environment, v. 74, p. 96-105, abr. 2014.

GHISI, E.; TINKER, J. A. An Ideal Window Area Concept For Energy Efficient Integration of Daylight and Artificial Light in Buildings.

Building and Environment, v. 40, n. 1, p. 51-61, jan. 2005.

LABORATÓRIO DE CONFORTO AMBIENTAL E EFICIÊNCIA ENERGÉTICA EM EDIFICAÇÕES. Arquivos Climáticos em Formato TRY, SWERA, CSV e BIN. Disponível em:

$<$ http://www.labeee.ufsc.br/downloads/arquivosclimaticos/formato-try-swera-csv-bin>. Acesso em: 1 nov. 2013.

LIMA, K. M. de; BITTENCOURT, L. S.; CARAM, R. M. Ranking Configurations of Shading Devices by Its Thermal and Luminous Performance. In: PLEA 2013: SUSTAINABLE ARCHITECTURE FOR A RENEWABLE FUTURE, 29., Munich, 2013. Anais... Munich: Fraunhofer IRB Verlag, 2013.

MANZAN, M. et al. Energy and Daylighting Optimization For an Office With Fixed and Moveable Shading Devices. In: BUILDING SIMULATION AND OPTIMIZATION CONFERENCE, 2., London, 2014. Proceedings... London: UCL, 2014.

NABIL, A; MARDALJEVIC, J. Useful Daylight Illuminances: a replacement for daylight factors. Energy and Buildings, v. 38, n. 7, p. 905-913, jul. 2006.

NIELSEN, M. V.; SVENDSEN, S.; JENSEN, L. B. Quantifying the Potential of Automated Dynamic Solar Shading in Office Buildings Through Integrated Simulations of Energy and Daylight. Solar Energy, v. 85, n. 5, p. 757-768, 2011.

NIMER, E. Climatologia do Brasil. Rio de Janeiro: IBGE, 1979. v. 4.

OCHOA, C. E. et al. Considerations on Design Optimization Criteria For Windows Providing
Low Energy Consumption and High Visual Comfort. Applied Energy, v. 95, p. 238-245, jul. 2012.

PEREIRA, F. O. R. Luminous and Thermal Performance of Window Shading and Sunlighting Reflecting Devices. Tese (Doutorado em Architectural Studies) - School of Architecture, University of Sheffield, 1992.

REINHART, C. F. DAYSIM 3.1. 2013.

Disponível em:

http://daysim.ning.com/page/download. Acesso em 31 mar. 2014.

ROULET, C. A. et al. ORME: a multicriteria rating methodology for buildings. Building and Environment, [S.1.], v. 37, [S.n.], p. 579-586, 2002.

SANTOS, C. M. L.; BASTOS, L. E. G. Influência dos elementos de fachada no desempenho da iluminação natural em edifícios de planta livre. In: ENCONTRO NACIONAL DE TECNOLOGIA NO AMBIENTE CONSTRUÍDO, 12., 2008. Fortaleza. Anais... Fortaleza: ANTAC, 2008.

TZEMPELIKOS, A. et al. Indoor thermal environmental conditions near glazed facades with shading devices - Part II: Thermal comfort simulation and impact of glazing and shading properties. Building and Environment, [S.1.], v. 45, [S.n.], p. 2517-2525, 2010.

TZEMPELIKOS, A.; ATHIENITIS, A.K. The impact of shading design and control on building cooling and lighting demand. Solar Energy, [S.1.], v. 81, n.3, p. 369-382, 2007.

U.S. DEPARTMENT OF ENERGY. EnergyPlus 7.2.0.006. Disponível em:

http://apps1.eere.energy.gov/buildings/energyplus/ . Acesso em: 2 maio 2013.

\section{Agradecimentos}

As autoras agradecem à FAPESP - Fundação de Amparo à Pesquisa do Estado de São Paulo, pela bolsa de doutorado que permitiu o desenvolvimento da pesquisa que originou este artigo. 


\section{Kamila Mendonça de Lima}

Instituto de Arquitetura e Urbanismo | Universidade de São Paulo | Av. Trabalhador São-Carlense, 400, Centro | São Carlos - SP - Brasil |

CEP 13566-590 | Tel.: (16) 3373-9285 | E-mail: kamila.arq.urb@gmail.com

\section{Rosana Maria Caram}

Instituto de Arquitetura e Urbanismo | Universidade de São Paulo | E-mail: rcaram@sc.usp.br

\section{Revista Ambiente Construído}

Associação Nacional de Tecnologia do Ambiente Construído

Av. Osvaldo Aranha, $99-3^{\circ}$ andar, Centro

Porto Alegre - RS - Brasil

CEP $90035-190$

Telefone: +55 (51) 3308-4084

Fax: +55 (51) 3308-4054

www.seer.ufrgs.br/ambienteconstruido

E-mail: ambienteconstruido@ufrgs.br 